\title{
Commentary \\ Recently published papers: Therapies failed, disputed, and beneficent
}

\author{
Gareth Williams
}

University Hospitals of Leicester, Leicester Royal Infirmary, Leicester, LE1 5WW, UK

Corresponding author: Gareth Williams, gareth.williams@uhl-tr.nhs.uk

Published: 18 June 2007

This article is online at http://ccforum.com/content/11/3/143

(c) 2007 BioMed Central Ltd
Critical Care 2007, 11:143 (doi:10.1186/cc5931)

ventilation, or number of ventilator-free days. It bestowed a small oxygenation benefit in the first few days of use. It did not significantly reduce mean pulmonary arterial pressure. High-dose NO (80 ppm) was associated with methaemoglobinaemia and raised blood nitrogen dioxide levels. Finally, a statistically significant risk for renal dysfunction was identified in patients receiving NO, although the authors stressed cautious interpretation of this finding.

This was an assiduously conducted review and the results are in keeping with previous work [2]. It leaves one begrudgingly accepting the authors' conclusions that, 'given the best available evidence suggests no survival advantage and possible increased mortality and renal dysfunction with nitric oxide, we do not recommend its routine use'.

\section{Drotrecogin alfa (activated): translating research into clinical practice}

Hardly a day seems to pass without further drotrecogin alfa (activated; DAA) scandal and controversy. Concerns centre on the widespread implementation of this drug in the treatment of severe sepsis, based upon a single industrysponsored trial and the applicability of this trial to 'real' patient populations. Many questions persist surrounding the indications for use and risk/benefit profile in patient subgroups. Bleeding risk is of particular concern.

Two recent publications are pertinent to this topic $[3,4]$. Bertolini and coworkers [3] reported a prospective pharmaco-surveillance programme monitoring the use of DAA in Italian ICUs between 2003 and 2006. The authors attempted to compare those who received DAA with a parallel nonrandomized untreated (control) group. The control group consisted of patients from a different study who were eligible for treatment with DAA but did not receive it. The authors reported a number of key observations. First, they

$\mathrm{AF}=$ atrial fibrillation; $\mathrm{CRRT}=$ continuous renal replacement therapy; $\mathrm{DAA}=$ drotrecogin alfa (activated); ICU $=$ intensive care unit; IHD $=$ intermittent haemodialysis; $\mathrm{NO}=$ nitric oxide; $\mathrm{ROSC}=$ return of spontaneous circulation. 
identified a high incidence of off-license prescribing. This was largely attributable to administration commencing more than 48 hours after the onset of organ dysfunction. More worryingly, they report a higher incidence of both serious bleeding and other fatal and life-threatening events compared with the previous landmark studies $[5,6]$. The also observed that intensive care unit (ICU) mortality rates for treatment and control groups ( $46.5 \%$ and $54.9 \%$, respectively) were much higher than the 28-day mortality in the aforementioned trials. This begs the question as to how well the PROWESS (Recombinant Human Activated Protein C Worldwide Evaluation of Severe Sepsis) population was representative of the real target population. The second report is of a retrospective observational study of the use of DAA in Canada. Findings are strikingly similar to those of the study reported by Bertolini and coworkers. Both mortality rate and the incidence of serious bleeding were significantly greater than in PROWESS. However, early treatment with DAA (within 12 hours) was an independent predictor of survival.

Neither of these studies allows firm conclusions to be drawn as to the optimal indication for DAA and the precise risk/ benefit profiles for various patient subgroups (for instance, surgical versus nonsurgical, or high versus low risk for death). However, they both cast further doubt as to the general applicability of PROWESS to the every day clinical setting and population. An accompanying editorial [7] emphasizes the urgent need for high quality, independent confirmatory research to identify those patients who are most likely to benefit from this therapy.

\section{Matters cardiac}

Atrial fibrillation (AF) is both common and troublesome. Newonset $\mathrm{AF}$ in the critically ill patient is related to the systemic inflammatory response, and is often refractory to treatments such as digoxin and amiodarone. A recent report published in the Journal of the American Medical Association [8] suggests that steroids are efficacious in prophylaxis against acute AF. A Finish group conducted a double blind randomized controlled trial, in which patients with no prior history of $A F$ undergoing cardiac surgery were randomly assigned to preoperative and postoperative (3 days) hydrocortisone or placebo. The incidence of postoperative AF was significantly lower in the steroid group (30\% versus $48 \%$ ). No adverse effects were noted. The authors postulate an anti-inflammatory mechanism, although they also suggest that the antiemetic effect of steroids is also of benefit in terms of absorption of oral medications such as metoprolol, which all patients received. Clearly, this group of patients exhibits a high incidence of AF, higher than that in the general ICU population, and steroids have only been shown to be efficacious in preventing $A F$ rather than treating established AF. As such, extrapolating this study to all ICU patients is probably flawed.

As alluded to above, translation of a therapeutic intervention from a clinical trial to reality is often fraught. This may be because of the study population not being representative of the target population, unrealistic/irreproducible protocols, or failure to capture the collective consciousness. In 2002, two papers were published in the New England Journal of Medicine that detailed evidence for improved outcomes following cardiac arrest with induced mild hypothermia $[9,10]$. August bodies such as the International Liaison Committee on Resuscitation have since recommended this therapeutic intervention, but is it happening on the shop floor? Arrich [11] decided to find out. In this observational study, data were collected from 19 European sites between 2003 and 2005. All patients presenting with return of spontaneous circulation (ROSC) after cardiac arrest were considered. Exclusions were similar to those in previous studies. The primary end-point was the cooling protocol, including the interval from arrest and ROSC to initiation of cooling, the cooling rate, cooling duration and re-warming rate. Secondary end-points were complications and neurological outcome. Results were very encouraging, with $79 \%$ of patients undergoing hypothermia. The median time from ROSC to cooling was 159 min, which was longer than that achieved in a recent clinical trial. However, the cooling rate of $1.1^{\circ} \mathrm{C} /$ hour was far superior to that in clinical trials. Cooling was maintained for an average of 24.3 hours. Rates of adverse events were lower than previously reported. Neurological outcome was better in the hypothermia group. This study demonstrates that therapeutic hypothermia is both feasible and safe in normal clinical practice, and that it benefits patients. No excuses then!

\section{Intermittent haemodialysis versus continuous renal replacement therapy}

Debate surrounding the pros and cons of intermittent haemodialysis (IHD) versus continuous renal replacement therapy (CRRT) in the ICU for the management of acute renal failure grumbles on. In the UK CRRT predominates, and serendipitously this appears to be the better choice. A Swedish group recently reported a large nationwide retrospective cohort study of renal outcome from acute renal failure following either IHD or CRRT $(n=2,202)$ [12]. Both groups were well matched before ICU admission, with an overall mortality of $50 \%$. There was no difference in 90 -day mortality between groups, which is in keeping with previous studies. However, patients treated with IHD were at significantly greater risk for chronic renal failure (need for renal replacement therapy at 3 months) and for being dialysis dependent, and unsurprisingly this group had the greatest long-term mortality. This was so despite data suggesting that patients in the CRRT group were sicker than those in the IHD group. Although clearly not a perfect study, this adds to the growing body of evidence indicating that CRRT is the renal replacement therapy of choice in the ICU. The authors suggest that a global re-evaluation of RRT in the ICU should now occur.

\section{Competing interests}

The author declares that they have no competing interests. 


\section{References}

1. Adhikari NKJ, Burns KEA, Friedrich JO, Granton JT, Cook DJ, Meade MO: Effect of nitric oxide on oxygenation in acute lung injury: systematic review and meta-analysis. BMJ 2007, 334: 779-782.

2. Sokol J, Jacobs SE, Bohn D: Inhaled nitric oxide for acute hypoxic respiratory failure in children and adults: a metaanalysis. Anesth Analg 2003, 97:989-998.

3. Bertolini G, Rossi C, Anghileri A, Livigni S, Addis A, Poole D: Use of Drotrecogin alfa (activated) in Italian intensive care units: the results of a national survey. Intensive Care Med 2007, 33: 426-434.

4. Kanji S, Perreault MM, Chant C, Williamson D, Burry L: Evaluating the use of Drotrecogin alfa (activated) in adult severe sepsis: a Canadian multicenter observational study. Intensive Care Med 2007, 33:517-523.

5. Bernard GR, Vincent JL, Laterre PF, LaRosa SP, Dhainaut JF, Lopez-Rodriguez A, Steingrub JS, Garber GE, Helterbrand JD, Ely $\mathrm{EW}$, et al.: Efficacy and safety of recombinant human activated protein C for severe sepsis. N Engl J Med 2001, 344:699-709.

6. Vincent JL, Bernard GR, Beale R, Doig C, Putensen C, Dhainaut JF, Artigas A, Fumagalli R, Macias W, Wright T, et al.: Drotrecogin alfa (activated) treatment in severe sepsis from the global open-label trial ENHANCE. Crit Care Med 2005, 33:22662277.

7. Eichacker $\mathrm{PQ}$, Natanson $\mathrm{C}$ : Increasing evidence that the risks of rhAPC may outweigh its benefits. Intensive Care Med 2007, 33:396-399.

8. Halonen J, Halonen P, Jarvinen O, Taskinen P, Auvinen T, Tarkka M, Hippelainen M, Juvonen T, Hartikainen J, Hakala T: Corticosteroids for the prevention of atrial fibrillation after cardiac surgery. JAMA 2007, 297:1562-1567

9. The Hypothermia after Cardiac Arrest Study Group: Mild therapeutic hypothermia to improve the neurologic outcome after cardiac arrest. N Engl J Med 2002, 346: 549-556

10. Bernard SA, Gray TW, Buist MD, Jones BM, Silvester W, Gutteridge G, Smith K: Treatment of comatose survivors of out-ofhospital cardiac arrest with induced hypothermia. $N$ Engl $J$ Med 2002, 346:557-563.

11. Arrich J; The European Resuscitation Council Hypothermia After Cardiac Arrest Registry Study Group: Clinical application of mild therapeutic hypothermia after cardiac arrest. Crit Care Med 2007, 35:1041-1047

12. Bell M, Granath F, Schon S, Ekbom A, Martling CR: Continuous renal replacement therapy is associated with less chronic renal failure than intermittent haemodialysis after acute renal failure. Intensive Care Med 2007, 33:773-780. 